\title{
Glycolysis of rigid polyurethane from waste refrigerators
}

\author{
Chao-Hsiung $\mathrm{Wu}^{\mathrm{a}, *}$, Ching-Yuan Chang ${ }^{\mathrm{b}}$, Jiunn-Kuen $\mathrm{Li}^{\mathrm{b}}$ \\ ${ }^{a}$ Department of Environmental Engineering, Da-Yeh University, Chang-hwa 515, Taiwan \\ ${ }^{\mathrm{b}}$ Graduate Institute of Environmental Engineering, National Taiwan University, Taipei 106, Taiwan
}

Received 9 April 2001; received in revised form 28 September 2001; accepted 21 October 2001

\begin{abstract}
Glycolysis of rigid polyurethane (PU) has been investigated to provide useful data for the recycling of waste refrigerators. The glycolysis experiments were performed under atmospheric pressure in a stirred flask kept at a constant temperature. Diethylene glycol (DEG) and potassium acetate (KAc) were used as the solvent and catalyst in the glycolysis system, respectively. The properties of the glycolysis products were determined by analyzing the hydroxyl value, mass mean molecular weight $\left(M_{\mathrm{w}}\right)$, viscosity, and the conversion of the $-\mathrm{NCOO}$ - functional group in PU. The results indicate that an adequate concentration of KAc is about $2 \%$ of the weight of the PU and an adequate reaction time is about $2 \mathrm{~h}$. The yields of glycolysis products are about $87-95 \%$ for our experimental conditions. Thus, the recovery of liquid products containing polyols can be achieved by the distillation of glycolysis products. (C) 2002 Elsevier Science Ltd. All rights reserved.
\end{abstract}

Keywords: Glycolysis; Polyurethane; Waste refrigerator

\section{Introduction}

Rigid polyurethane (PU), a heat insulating material, is one of the principal components of a refrigerator. In Taiwan, the amount of waste rigid PU from the recycling of refrigerators is about 2500 tons per year. On the basis of the current recycling frameworks promoted by the Republic of China Environmental Protection Administration, Taiwan, waste refrigerators have been a significant resource. The major methods for treating waste PU include landfill, incineration, and material recycling. The glycolysis of waste PU into raw materials is one of the principal methods for material recycling [1]. Some studies and reviewed literature indicate that a proper glycolysis may be used to resolve the disposal problems of waste PU and obtain high quality polyols (raw materials of PU) from waste PU [1-6].

Many researchers have investigated the glycolysis of waste PU. These studies have been concerned mostly with glycolysis mechanisms, formulation of glycolysis, effects of catalysts on glycolysis, properties of the foams from the recycled polyols, and purification of glycolysis

* Corresponding author. Tel.: +886-4-8511331; fax: +886-48511332.

E-mail address: chwu@mail.dyu.edu.tw (C.-H. Wu). products. Kinoshita [7] discussed the thermal dissociation of flexible PU in various glycols (two to six carbon atoms, such as ethylene glycol (EG), propylene glycol, and butylene glycol). In his investigation, the temperature employed in the dissociation reaction ranged preferably from 443 to $458 \mathrm{~K}$, with tertiary amine as the catalyst. The weight of glycol was at least the same, and preferably 2-3 times the weight of the PU resin. The products separated into two layers upon cooling and standing, the upper layer being a polyalkylene ether of a polyol, and the lower layer being a glycol containing amine compounds. Frulla et al. [8] investigated the reaction conditions for the conversion of scrap rigid $\mathrm{PU}$ foam to polyols. In their investigation, a combination of diethylene glycol (DEG) and approximately $5 \%$ by weight of diethanolamine (DEA) was found to be especially useful in the recovery of scrap PU. Tucker and Ulrich [9] studied the glycolysis process for converting scrap flexible PU foam to a homogeneous mixture of polyols. The recovered polyol was useful particularly in the preparation of new rigid PU foam. Kondo et al. [10] provided a process for obtaining a polyol-containing homogeneous liquid composition from rigid PU foams. The glycolysis of PU was performed at $423-493 \mathrm{~K}$ in the presence of a mixture of aliphatic diol and a monoalkanolamine. The recovered polyol was useful in the pre- 
paration of rigid PU foam. Sheratte [11] reported a process for converting a depolymerized reaction product containing amines into polyols with ethylene oxide or propylene oxide at 393-413 K, thereby permitting efficient recovery and re-use of otherwise-useless scrap PU materials. Ulrich et al. [12] examined the glycolysis of thermoset PU elastomers. Glycolysis of reaction injection molding grade (RIM) PU was implemented at 488-503 K with an equal amount of dipropylene glycol (DPG). The results indicated that a level of $50 \%$ of recycled polyol could be tolerated without detrimentally affecting the physical properties of the derived foam. Simioni and Bisello [13] examined the glycolysis mechanisms and the properties of the glycolysis products of PU scraps from industrial slab stock. Laboratory runs were performed under nitrogen. The results indicated that the best reagent and catalyst for obtaining high quality polyols were DPG and potassium acetate (KAc). The products from the glycolysis of PU can be used without further treatment for the production of rigid urethane foams. Simioni et al. [14] investigated the glycolysis of PU elastomer waste, mainly from shoe sole production. The experiments were carried out at temperature of 453-493 K with or without added catalysts (DEG and DPG). The waste and scrap PU could be converted into polyols, which could be reused in the production of rigid foams. Simioni et al. [15] investigated the possibility of conversion of microcellular polyurethane elastomers (MPE) into raw materials in the preparation of polyurethane-polyisocyanurate rigid foams. The effects of functionality, content of isocyanurate, and $\mathrm{MDI} /$ polyol weight ratio on the properties of new foams were discussed in detail. Modesti et al. [16] investigated the possibility of recycling MPE waste and scraps in the production of new MPE. The transformation of glycolysis products into mixtures of polyesters with $M_{\mathrm{w}}$ of about 2000 allowed a better use of the glycolysis products in elastomer production. Simioni and Modesti [17] investigated the glycolysis products of flexible PU foams. Their results indicated that the use of EG allowed the process to be carried out with high polymer/glycol ratio (up to 4:1). A polyphasic product was obtained. The final product of the research met the main requirements for a material for general use in the preparation of RIM PU. Kerscher et al. [18] investigated the glycolysis of foamed PU from automotive interiors. High-quality glycolysates were obtained from the glycolysis of RIM and RRIM-PU. The results indicated that glycolysates with approximately $50-70 \%$ recycled PU showed good overall processing behaviour. Borda et al. [19] investigated the glycolysis of flexible PU foams and elastomers. The reagents used for the experiments were glycols and diethanolamine. In their study, the optimum conditions for the glycolysis of flexible PU foams and elastomers were obtained. The polyol component was separated from the two-phase liquid mixture and could be used as an industrial adhesive.
The glycolysis products of rigid PU foams depend not only on the chemical-physical nature of polymers but also on the temperature, catalysts, type of glycols and glycol/polymer ratio [6]. The effects of temperature and catalysts on the glycolysis products have been investigated in related literature [14,20]. Also, the amine content in the recovered polyols is an important index for the reuse as feedstocks. Typically, at a temperature greater than $493 \mathrm{~K}$, unwanted secondary reaction rates become competitive with respect to transesterification reactions, leading to a product with considerable amine content $[6,14]$. The use of potassium acetate is known to increase the amounts of amines in the glycolysis products of rigid PU foams $[6,20]$. Low amine content products may be obtained by adding chemical reagents to the glycolysis system [21-23]. Gassan et al. [21] examined recycled polyols obtained by glycolysis of PUs and/or polyureaPUs. Their results indicated that a low-amine and homogeneous recycled polyol could be obtained by adding glycidyl ethers to the reaction mixture. Van der Wal [22] proposed a two-step glycolysis process. In the first step the polymer is broken down with an alkanolamine and a catalyst into a highly concentrated emulsiondispersion of carbamates, ueras, amines and polyol. In the second step, this emulsion-dispersion is alkoxylated to remove any aromatic amine and to obtain a relatively high-performance, low-color, high-functional polyol. Toluene di-isocyanate (TDI)-base flexible slab stock foam and reinforced RIM (RRIM) materials were efficiently converted to relatively high-performance polyols by the two-step glycolysis process. Modesti et al. [23] explored the glycolysis of flexible PU foams. The experiments were implemented in the presence of EG and an organometallic catalyst, under an inert environment and at the boiling temperature of EG. The results indicated that the use of EG allowed the process to be implemented with a high polymer/glycol ratio (up to $4: 1$ ). The low aromatic amine content products can be used in the production of new polymers.

The results of previous studies provide some information about the glycolysis of flexible/rigid PU, RIM/ RRIM PU, PU elastomers, PU from industrial slab stock or automotive interiors, and the recycling of $\mathrm{PU}$ foams with low amine content. However, the properties of rigid PU foam used as insulating material in refrigerators may differ from those investigated. Also, the choice of solvent and catalyst, as well as the reaction time is an important factor affecting glycolysis products for further foaming. It was thus the aim of the present study to determine the optimum glycolysis conditions (time, solvent, and catalyst level) for the treatment of the waste rigid PU from recycled refrigerators. Diethylene glycol (DEG) and potassium acetate (KAc) were used as the solvent and catalyst, respectively. The experiments for the glycolysis of rigid PU foam were performed under atmospheric pressure and in a stirred 
Table 1

Specifications and elemental analysis of polyurethane rigid foam

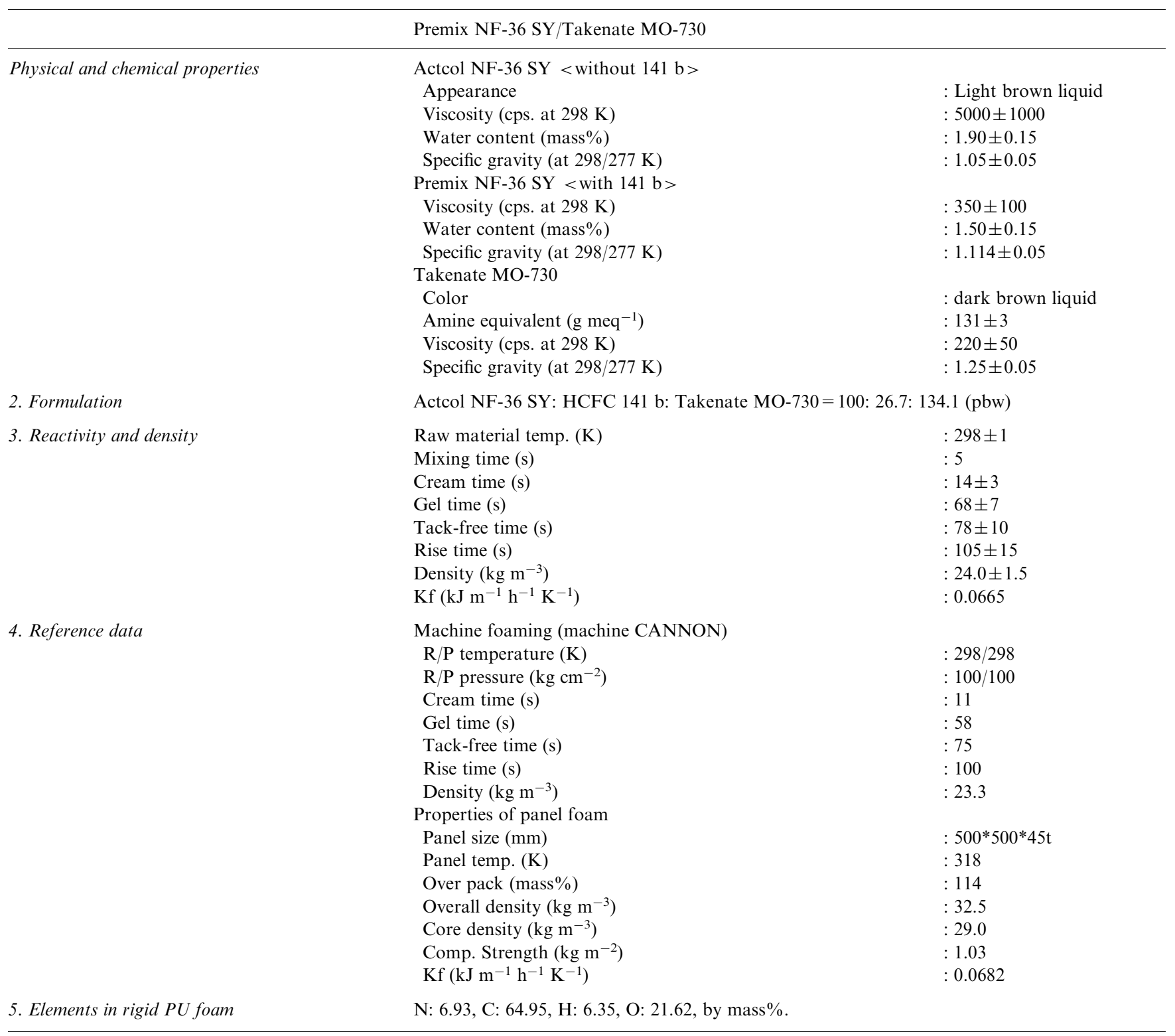

flask kept at a constant temperature $(496 \pm 3 \mathrm{~K})$ below the boiling point of DEG (517-518 K). The effects of the reaction time $(\mathrm{t})$ and the concentrations of DEG and $\mathrm{KAc}$ in the mixture on the properties of glycolysis products were investigated.

\section{Experimental}

Commercial-grade rigid PU foam with the same properties as the waste PU from recycled refrigerators was used in this study. The properties of the PU sample are listed in Table 1. The particle size distribution of the pulverized rigid PU foam is shown in Table 2. The experiments consist of three parts: glycolysis of rigid PU foam, purification of glycolysis products, and analysis of the products.

The process flow diagram of the glycolysis system is shown in Fig. 1. The operating conditions and the glycolysis runs with different formulations of the solvent (DEG) and the catalyst (KAc) are listed in Table 3. A 2 $\mathrm{dm}^{3}$ Pyrex flask reactor equipped with an agitator was used. The glycolysis experiments were performed under atmospheric pressure. Known masses of the solvent and catalyst were placed in the reactor first. The speed of the stirrer was set at $1050 \pm 50 \mathrm{rpm}$ and the temperature of the heating mantle set at $496 \pm 3 \mathrm{~K}$. When the temperature of the mixture (DEG and KAc) reached the specified value, the pulverized rigid PU foam was fed by a screw feeder. The feeding rate was $1.5-3 \mathrm{~g} \mathrm{~min}{ }^{-1}$ 
Table 2

Particle size distribution of rigid PU foam

\begin{tabular}{lc}
\hline Size range $(\mathrm{mm})$ & Mass percent $(\%)$ \\
\hline $0-0.149$ & 5.64 \\
$0.149-0.297$ & 12 \\
$0.297-0.84$ & 74 \\
$0.84-2$ & 7.6 \\
$>2$ & 0.76
\end{tabular}

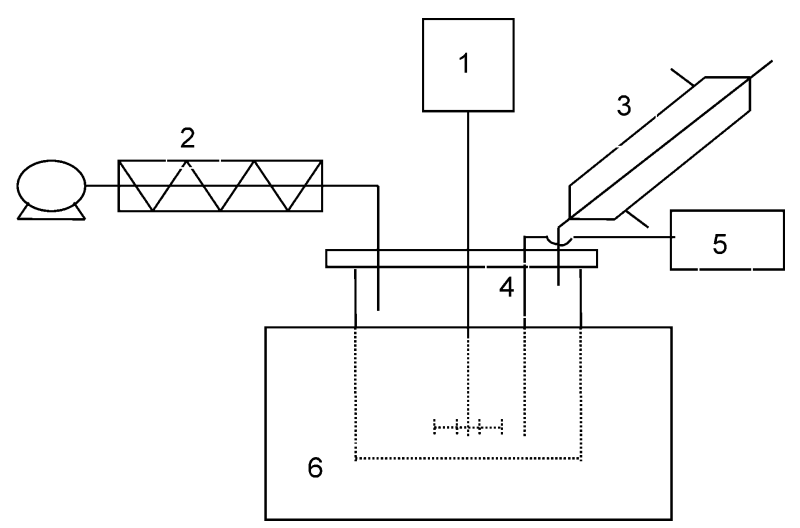

Fig. 1. Schematic diagram of apparatus for glycolysis of waste polyurethane foam. 1, stirrer; 2, screw feeder; 3, condenser; 4, thermocouple; 5 , temperature controller; 6 , heating mantle.

Table 3

Glycolysis under different operating conditions

\begin{tabular}{|c|c|c|c|}
\hline \multirow{5}{*}{$\begin{array}{l}\text { Operating } \\
\text { conditions: }\end{array}$} & \multicolumn{2}{|c|}{ Solvent/catalyst: } & \multirow{5}{*}{$\begin{array}{l}\mathrm{DEG} / \mathrm{CH}_{3} \mathrm{COOK} \\
(\mathrm{KAc}) \\
493-499 \\
1000-1100 \\
1.5-3 \\
1\end{array}$} \\
\hline & \multirow{4}{*}{\multicolumn{2}{|c|}{$\begin{array}{l}\text { Liquid-phase temperature }(\mathrm{K}) \text { : } \\
\text { Stirring speed }(\mathrm{rpm}): \\
\text { Feeding rate }\left(\mathrm{g} \mathrm{min}^{-1}\right) \text { : } \\
\text { System pressure }(\mathrm{atm}) \text { : }\end{array}$}} & \\
\hline & & & \\
\hline & & & \\
\hline & & & \\
\hline Run number & $\begin{array}{l}\text { DEG/PU } \\
(\operatorname{mass} \%)\end{array}$ & $\begin{array}{l}\mathrm{KAc} / \mathrm{PU} \\
(\mathrm{mass} \%)\end{array}$ & $\begin{array}{l}\text { Mass of PU } \\
(\mathrm{g})\end{array}$ \\
\hline A011 & 300 & 0.5 & 40.2 \\
\hline A012 & 300 & 2.0 & 40.0 \\
\hline A 013 & 300 & 5.0 & 40.0 \\
\hline A014 & 200 & 0.5 & 59.8 \\
\hline $\mathrm{A} 015$ & 200 & 2.0 & 60.0 \\
\hline A016 & 200 & 5.0 & 60.1 \\
\hline A017 & 100 & 0.5 & 120.3 \\
\hline A018 & 100 & 2.0 & 119.8 \\
\hline A019 & 100 & 5.0 & 120.1 \\
\hline
\end{tabular}

according to the rate of dissolution. Simultaneously, the feeding time and the reaction time (starting at the end of the feeding the PU sample) were recorded. The glycolysis products were sampled at reaction times of $0.5,1$, $2,3,4,5$ and $6 \mathrm{~h}$, respectively. The glycolysis products were collected after the reactor was cooled to room temperature.

A $0.5 \mathrm{dm}^{3}$ flask with a shell and tube condenser was used as a still. The glycolysis products were distilled to obtain the polyol-containing liquid products. The distilled materials were collected at various distillation temperature (gas-phase temperature) ranges of $<518$, $518-523,524-565$ and $>565 \mathrm{~K}$, respectively.

The properties of the glycolysis products, such as hydroxyl value $\left(\mathrm{mg} \mathrm{KOH} \mathrm{g}^{-1}\right)$, conversion $(\mathrm{X})$ of NCOO- functional group in PU, mass mean molecular weight, and viscosity at different experimental conditions were analysed. The hydroxyl value was determined by the titration method (ASTM D2849 method B: pressurebottle phthalation). The mass mean molecular weight was determined by gel permeation chromatography (GPC). The GPC system consists of an ABI Analytical Kratos Division pumping system, a Shodex RI-71 detector, a SIC chromatocorder-12 integrator, and a Plgel Guard Column. The standards used for determining the $M_{\mathrm{w}}$ of the glycolysis products were polystyrene (TSK standard, $\mathrm{TOSOH}$, Japan). Conversion of the $-\mathrm{NCOO}-$ functional group in PU was determined by Fourier transform infrared spectroscopy (FTIR, BIO-RAD, FTS-40) equipped with a DTGS detector. The viscosity was determined by a Brookfield viscometer (model: LVT $115 \mathrm{v} / 60 \mathrm{HZ}$ ). The elemental analysis for the rigid PU foam sample was made on a Perkin-Elmer, Norwalk, CT 2400 elemental analyzer. The properties of the distilled materials were analyzed by the same methods as those of the glycolysis products.

\section{Results and discussion}

\subsection{Properties of glycolysis products}

The hydroxyl values of the glycolysis products of rigid PU foam at different reaction times are listed in Table 4. They are about $609-946 \mathrm{mg} \mathrm{KOH} \mathrm{g}^{-1}$. The variation in the hydroxyl value of the glycolysis products with different reaction times is shown in Fig. 2. In general, the hydroxyl value increased when the reaction time increased. It is noted that after a reaction time of $2 \mathrm{~h}$, the hydroxyl value reaches nearly constant values for the experimental runs with higher concentrations of DEG and KAc (i.e. A015, A016, A018, and A019), indicating that DEG and KAc enhance the glycolysis of PU foam and shorten the reaction time. Variation in the hydroxyl value of the glycolysis products at $t=2 \mathrm{~h}$ with concentration of KAc is shown in Fig. 3. Higher hydroxyl values are obtained at higher DEG concentrations, which may be ascribed to the effects of DEG on the glycolysis. Also, the hydroxyl value of pure DEG is $1057.3 \mathrm{mg} \mathrm{KOH} \mathrm{g}^{-1}$. Because the excess DEG is not separated from the glycolysis products, the hydroxyl value may be partly attributed to that of pure DEG. At a lower DEG concentration $(\mathrm{DEG} / \mathrm{PU}=100 \%)$ the $\mathrm{CH}_{3} \mathrm{COOK}$ enhances the glycolysis significantly. The hydroxyl value reaches constant values, when $\mathrm{KAc} /$ $\mathrm{PU}=2 \%$ for three DEG concentrations. 
The extent of PU glycolysis can also be observed from the conversion $(\mathrm{X})$ of the $-\mathrm{NCOO}$ - functional group in the urethane. Because the aromatic ring in $\mathrm{PU}$ is more stable than is the - NCOO- functional group and is not destroyed in the glycolysis temperature range, the conversion of the -NCOO- functional group in PU is estimated by the relative absorption intensity of the NCOO- (at about $1720 \mathrm{~cm}^{-1}$ ) to that of the aromatic

Table 4

Hydroxyl values of glycolysis products at different reaction times

\begin{tabular}{llllllllc}
\hline Run number & \multicolumn{7}{l}{ Hydroxyl value $\left(\mathrm{mg} \mathrm{KOH} \mathrm{g}^{-1}\right)$} \\
\cline { 2 - 9 } & $0.5 \mathrm{~h}$ & $1 \mathrm{~h}$ & $2 \mathrm{~h}$ & $3 \mathrm{~h}$ & $4 \mathrm{~h}$ & $5 \mathrm{~h}$ & $6 \mathrm{~h}$ \\
\cline { 2 - 9 } & 888.8 & 899.6 & 903.9 & - & - & - & - \\
A012 & 909.8 & 928.5 & 942.2 & - & - & - & - \\
A013 & 934.2 & 946.9 & 935.5 & - & - & - & - \\
A014 & 786.9 & 795.7 & 809.5 & 822.6 & 854.7 & 863.9 & 867.0 \\
A015 & 841.8 & 860.6 & 885.5 & 883.1 & 881.6 & 880.1 & 873.0 \\
A016 & 861.6 & 864.6 & 897.3 & 899.9 & 898.3 & 899.0 & 886.0 \\
A017 & 609.4 & 611.4 & 625.2 & 643.3 & 657.6 & 665.4 & 673.8 \\
A018 & 709.2 & 714.4 & 774.3 & 795.2 & 801.9 & 805.3 & 807.9 \\
A019 & 758.2 & 774.8 & 782.0 & 781.2 & 793.5 & 798.1 & 790.6 \\
\hline
\end{tabular}

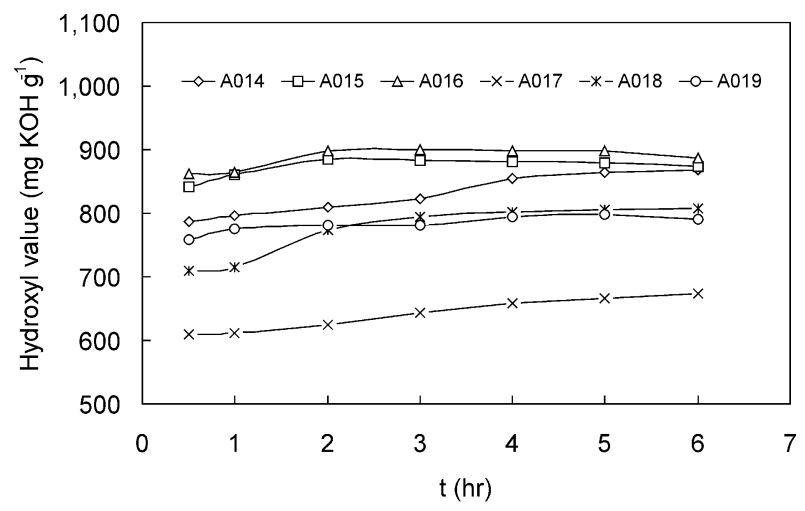

Fig. 2. Variation in hydroxyl value of glycolysis products with reaction times $(t)$. A014, A015, A016, A017, A018, A019: DEG/PU and $\mathrm{KAc} / \mathrm{PU}=200$ and $0.5 \%, 200$ and $2 \%, 200$ and $5 \%, 100$ and $0.5 \%$, 100 and $2 \%, 100$ and $5 \%$.

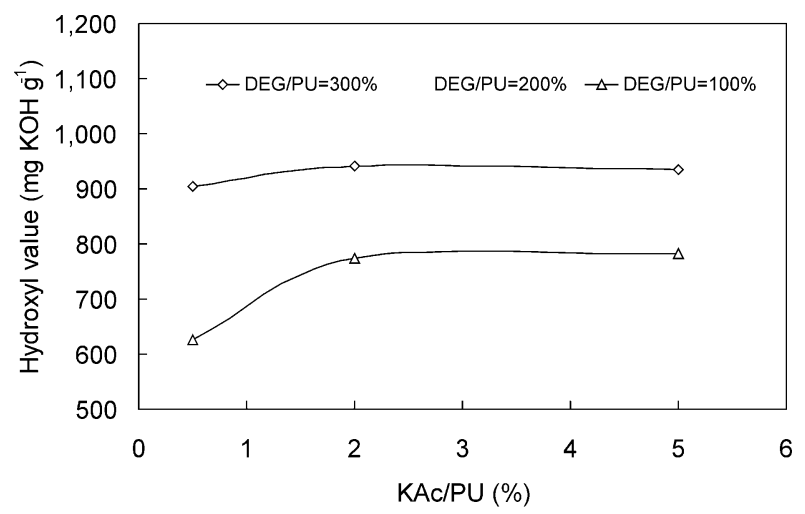

Fig. 3. Variation in hydroxyl value of glycolysis products at $t=2 \mathrm{~h}$ with concentration of catalyst (KAc/PU). ring, $-\mathrm{Ar}$, (at about $1450 \mathrm{~cm}^{-1}$ ). The results are summarized in Table 5. The conversion of -NCOO- varies with the reaction time and concentrations of DEG and

Table 5

Conversion of - $\mathrm{NCOO}-$ in $\mathrm{PU}$ at different experimental conditions

\begin{tabular}{|c|c|c|c|c|}
\hline \multirow[t]{2}{*}{ Run } & \multicolumn{2}{|c|}{ Absorption intensity } & \multirow{2}{*}{$\frac{\text { Relative intensity }}{[-\mathrm{NCOO}-]_{\mathrm{r}}{ }^{\mathrm{d}}}$} & \multirow{2}{*}{$\begin{array}{l}\text { Conversion } \\
\text { of -NCOO-e } \\
(\%)\end{array}$} \\
\hline & {$[-\mathrm{NCOO}-]^{\mathrm{b}}$} & {$[-\mathrm{Ar}]^{\mathrm{c}}$} & & \\
\hline PU foam & 0.2864 & 0.1977 & 1.4487 & - \\
\hline $\mathrm{A} 011-0.5^{\mathrm{a}}$ & 0.1709 & 0.2862 & 0.5971 & 58.8 \\
\hline A011-1 & 0.1042 & 0.2481 & 0.4200 & 71.0 \\
\hline A011-2 & 0.0428 & 0.1367 & 0.3131 & 78.4 \\
\hline A $012-0.5$ & 0.2329 & 0.4762 & 0.4891 & 66.2 \\
\hline A012-1 & 0.0985 & 0.3304 & 0.2981 & 79.4 \\
\hline A $012-2$ & 0.0702 & 0.3763 & 0.1866 & 87.1 \\
\hline A $013-0.5$ & 0.0183 & 0.2075 & 0.0882 & 93.9 \\
\hline A013-1 & 0.0292 & 0.3448 & 0.0847 & 94.2 \\
\hline A $013-2$ & 0.0280 & 0.3333 & 0.0840 & 94.2 \\
\hline A $014-0.5$ & 0.4217 & 0.4089 & 1.0313 & 28.8 \\
\hline A014-1 & 0.4294 & 0.4428 & 0.9697 & 33.1 \\
\hline A $014-2$ & 0.2726 & 0.2953 & 0.9231 & 36.3 \\
\hline A $014-3$ & 0.4717 & 0.5480 & 0.8608 & 40.6 \\
\hline A014-4 & 0.9065 & 1.2015 & 0.7545 & 47.9 \\
\hline A $014-5$ & 0.4219 & 0.5288 & 0.7978 & 44.9 \\
\hline A014-6 & 0.3107 & 0.3874 & 0.8020 & 44.6 \\
\hline A $015-0.5$ & 0.3765 & 0.6373 & 0.5908 & 59.2 \\
\hline A015-1 & 0.2759 & 0.7146 & 0.3861 & 73.3 \\
\hline A $015-2$ & 0.2018 & 0.8054 & 0.2506 & 82.7 \\
\hline A $015-3$ & 0.2207 & 0.8017 & 0.2753 & 81 \\
\hline A $015-4$ & 0.2239 & 0.6036 & 0.3709 & 74.4 \\
\hline A015-5 & 0.1143 & 0.2885 & 0.3962 & 72.7 \\
\hline A016-0.5 & 0.1526 & 0.4217 & 0.3619 & 75.0 \\
\hline A016-1 & 0.0730 & 0.3240 & 0.2253 & 84.4 \\
\hline A $016-2$ & 0.0503 & 0.3150 & 0.1597 & 89.0 \\
\hline A016-3 & 0.0626 & 0.3199 & 0.1956 & 86.5 \\
\hline A016-4 & 0.0831 & 0.3279 & 0.2535 & 82.5 \\
\hline A016-5 & 0.1046 & 0.3358 & 0.3115 & 78.5 \\
\hline A $017-0.5$ & 0.5325 & 0.4965 & 1.0725 & 26.0 \\
\hline A017-1 & 0.2060 & 0.1927 & 1.0690 & 26.2 \\
\hline A $017-2$ & 0.2483 & 0.2205 & 1.1261 & 22.3 \\
\hline A $017-3$ & 0.1712 & 0.1681 & 1.0184 & 29.7 \\
\hline A $017-4$ & 0.1542 & 0.1554 & 0.9924 & 31.5 \\
\hline A017-5 & 0.1197 & 0.1279 & 0.9359 & 35.4 \\
\hline A $018-0.5$ & 0.3836 & 0.3757 & 1.0210 & 29.5 \\
\hline A018-1 & 0.4480 & 0.4860 & 0.9218 & 36.4 \\
\hline A018-2 & 0.1527 & 0.2401 & 0.6360 & 56.1 \\
\hline A018-3 & 0.2240 & 0.4400 & 0.5091 & 64.9 \\
\hline A018-4 & 0.1769 & 0.3310 & 0.5344 & 63.1 \\
\hline A018-5 & 0.1773 & 0.2843 & 0.6236 & 57.0 \\
\hline A019-0.5 & 0.2975 & 0.3653 & 0.8144 & 43.8 \\
\hline A019-1 & 0.1989 & 0.4112 & 0.4837 & 66.6 \\
\hline A $019-2$ & 0.1554 & 0.5429 & 0.2862 & 80.2 \\
\hline A $019-3$ & 0.0885 & 0.3114 & 0.2842 & 80.4 \\
\hline A $019-4$ & 0.1502 & 0.4242 & 0.3541 & 75.6 \\
\hline A019-5 & 0.1971 & 0.3751 & 0.5255 & 63.7 \\
\hline
\end{tabular}

a $A^{* * *}-0.5,-1,-2,-3,-4,-5,-6$ : reaction time $=0.5,1,2,3,4,5,6 \mathrm{~h}$, respectively.

b [-NCOO-]: intensity of absorption peak of -NCOO- at about $1720 \mathrm{~cm}^{-1}$.

c [-Ar]: intensity of absorption peak of $-\mathrm{Ar}$ at about $1450 \mathrm{~cm}^{-1}$.

d $[-\mathrm{NCOO}-]_{\mathrm{r}}=[-\mathrm{NCOO}-] /[-\mathrm{Ar}]$.

e Conversion of $-\mathrm{NCOO}-=1-\left([-\mathrm{NCOO}-]_{\mathrm{r}}\right.$ of glycolysis products $) /$ $\left([-\mathrm{NCOO}-]_{\mathrm{r}}\right.$ of rigid $\mathrm{PU}$ foam $)$. 
$\mathrm{CH}_{3} \mathrm{COOK}$ and is in the range of $22-94 \%$ under the experimental conditions. The variation in the FTIR spectrum of the glycolysis products with the reaction time for $\mathrm{DEG} / \mathrm{PU}=100 \%$ and $\mathrm{KAc} / \mathrm{PU}=0.5 \%$ is shown in Fig. 4. The absorption intensity of $-\mathrm{NCOO}-$ varies inversely with the reaction time. The variation in the conversion of $-\mathrm{NCOO}$ - with the reaction time is shown in Fig. 5. The trend is similar to that of the hydroxyl value in Fig. 2. The maximum conversions are observed at $t=2 \mathrm{~h}$ for the experimental runs with higher concentrations of DEG and KAc (i.e. A015, A016, A019) and $t=3 \mathrm{~h}$ for A018. For lower concentrations of DEG and KAc (i.e. A014, A017), the -NCOO- conversion varies with the reaction time. The effects of DEG and KAc on the glycolysis reaction are similar to the results in the hydroxyl value analysis. The variation in the $-\mathrm{NCOO}-$ conversion at $t=2 \mathrm{~h}$ with the concentration of KAc is shown in Fig. 6. For the same reaction time, the conversions of $-\mathrm{NCOO}-$ at $\mathrm{KAc} / \mathrm{PU}=0.5,2$ and $5 \%$ are $78.4,87.1$ and $94.2 \%$ for $\mathrm{DEG} / \mathrm{PU}=300 \%, 36.3$, 82.7 and $89.0 \%$ for DEG/PU $=200 \%$, and $22.3,56.1$ and $80.2 \%$ for $\mathrm{DEG} / \mathrm{PU}=100 \%$, respectively. The presence of DEG and KAc enhances the conversion of NCOO- and thus the glycolysis of PU, which is consistent with the increasing hydroxyl value as indicated in the preceding section. Examining Figs. 2, 3, 5 and 6, the results suggest that an adequate concentration of KAc is about $2 \%$ of PU and an adequate reaction time is about $2 \mathrm{~h}$. In these conditions the conversion of $-\mathrm{NCOO}-$ will be higher than $80 \%$ for DEG/PU $=200$ and $300 \%$.

The $M_{\mathrm{w}}$ of glycolysis product at different reaction times is listed in Table 6 . The $M_{\mathrm{w}}$ is in the range of $441-$ 1296 for a reaction time of $2 \mathrm{~h}$. The $M_{\mathrm{w}}$ of glycolysis products with reaction times for the experimental runs with higher concentrations of DEG and KAc (i.e. A015, A016, A018, A019) is shown in Fig. 7. It is also noted that the $M_{\mathrm{w}}$ reaches constant values at $t=2 \mathrm{~h}$. To check the effects of the catalyst on the glycolysis, the variation in the $M_{\mathrm{w}}$ with the concentration of KAc at $t=2 \mathrm{~h}$ is shown in Fig. 8. Higher DEG and KAc concentrations result in a lower molecular weight. The values of $M_{\mathrm{w}}$ at $\mathrm{KAc} / \mathrm{PU}=2,5 \%$ are 489,441 for $\mathrm{DEG} / \mathrm{PU}=300 \%$ and 547, 492 for $\mathrm{DEG} / \mathrm{PU}=200 \%$, respectively. These values are nearly the same or lower than those of the other experimental conditions (i. e. $\mathrm{DEG} / \mathrm{PU}=100 \%$ ), thereby further indicating that an adequate concentration of KAc is about $2 \%$ of PU and an adequate reaction time is $2 \mathrm{~h}$.

The viscosity of an original polyol (Actcol NF-36 SY) is about $5000 \pm 1000 \mathrm{cps}$. The viscosity of the glycolysis

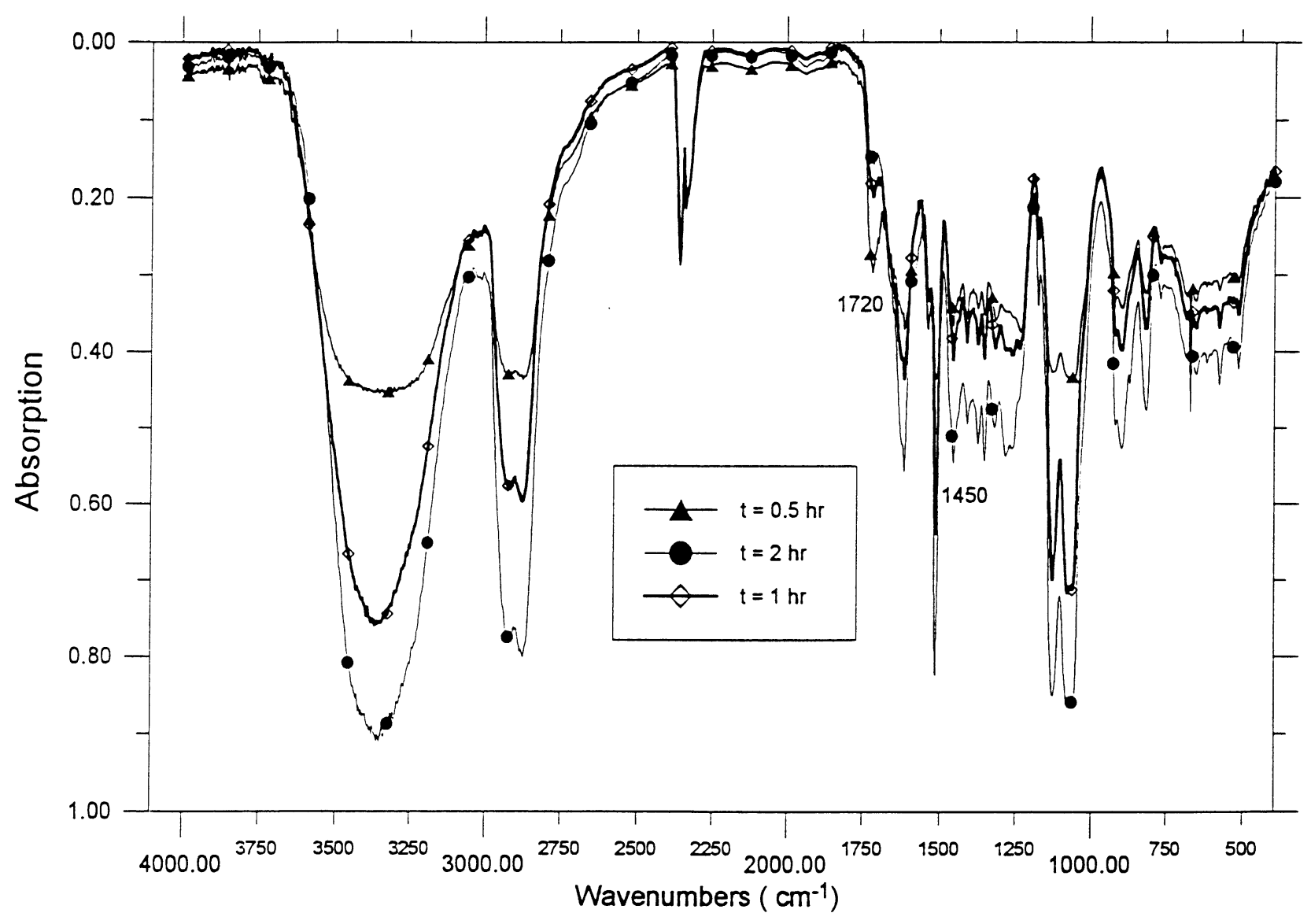

Fig. 4. Variation in FTIR spectrum of glycolysis products with reaction time $(t)$. DEG $/ \mathrm{PU}=100 \%, \mathrm{KAc} / \mathrm{PU}=0.5 \%$. 


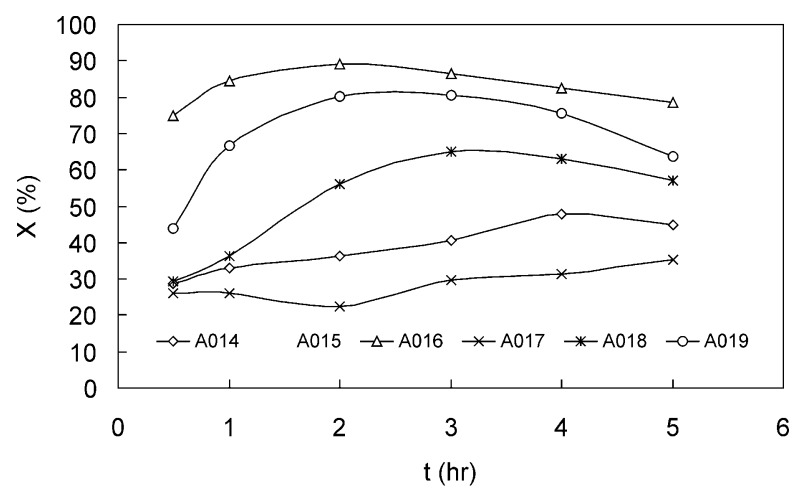

Fig. 5. Variation in conversion $(\mathrm{X})$ of $-\mathrm{NCOO}-$ in $\mathrm{PU}$ with reaction times $(t)$. A014, A015, A016, A017, A018, A019: DEG/PU and KAc/ $\mathrm{PU}=200$ and $0.5 \%, 200$ and $2 \%, 200$ and $5 \%, 100$ and $0.5 \%, 100$ and $2 \%, 100$ and $5 \%$.

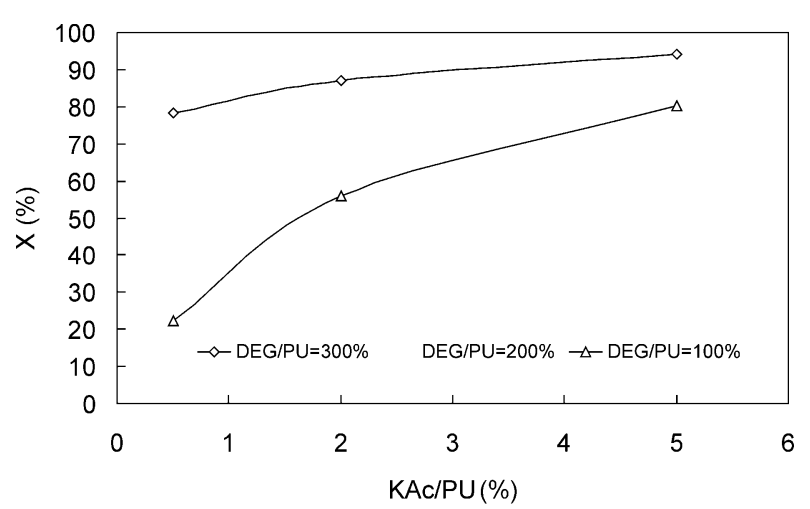

Fig. 6. Variation in conversion (X) of $-\mathrm{NCOO}-$ in $\mathrm{PU}$ at $t=2 \mathrm{~h}$ with concentration of catalyst (KAc/PU).

Table 6

Mass mean molecular weights $\left(M_{\mathrm{w}}\right)$ of glycolysis products at different reaction times

\begin{tabular}{lrrrrrrr}
\hline Run number & \multicolumn{1}{l}{$M_{\mathrm{w}}$} \\
\cline { 2 - 8 } & $0.5 \mathrm{~h}$ & $1 \mathrm{~h}$ & $2 \mathrm{~h}$ & $3 \mathrm{~h}$ & $4 \mathrm{~h}$ & $5 \mathrm{~h}$ & $6 \mathrm{~h}$ \\
\hline A011 & 660 & 592 & 628 & - & - & - & - \\
A012 & 621 & 518 & 489 & - & - & - & - \\
A013 & - & - & 441 & - & - & - & - \\
A014 & 997 & - & 892 & - & 783 & - & - \\
A015 & 703 & 641 & 547 & 540 & 536 & 533 & 530 \\
A016 & 625 & 547 & 492 & 508 & 516 & 511 & 502 \\
A017 & 1614 & - & 1296 & - & - & - & 1,281 \\
A018 & 1174 & 1107 & 733 & 751 & 745 & 760 & 748 \\
A019 & 963 & 757 & 603 & 607 & 610 & 616 & 621 \\
\hline
\end{tabular}

products for a reaction time of $2 \mathrm{~h}$ is listed in Table 7 and shown in Fig. 9. These values, which are about 90 $3252 \mathrm{cps}$ and are lower than those of the original polyol, indicate that the excess DEG and the low-molecular polyol-containing products may be recycled into a fresh stream as solvents.

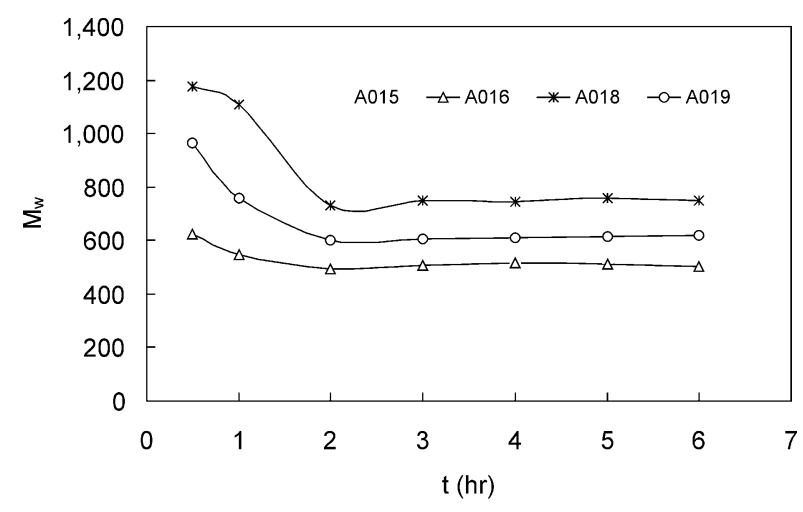

Fig. 7. Variation in mass mean molecular weight $\left(M_{\mathrm{w}}\right)$ of glycolysis products with reaction times $(t)$. A015, A016, A018, A019: DEG/PU and $\mathrm{KAc} / \mathrm{PU}=200$ and $2 \%, 200$ and $5 \%, 100$ and $2 \%, 100$ and $5 \%$.

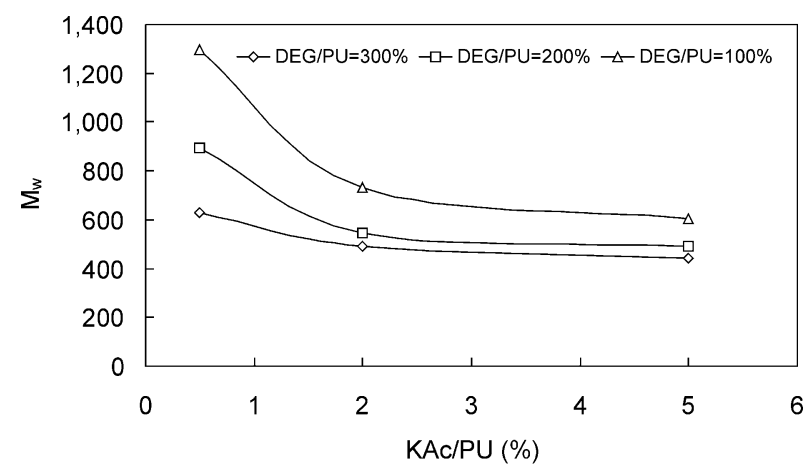

Fig. 8. Variation in mass mean molecular weight $\left(M_{\mathrm{w}}\right)$ of glycolysis products at $t=2 \mathrm{~h}$ with concentration of catalyst (KAc/PU).

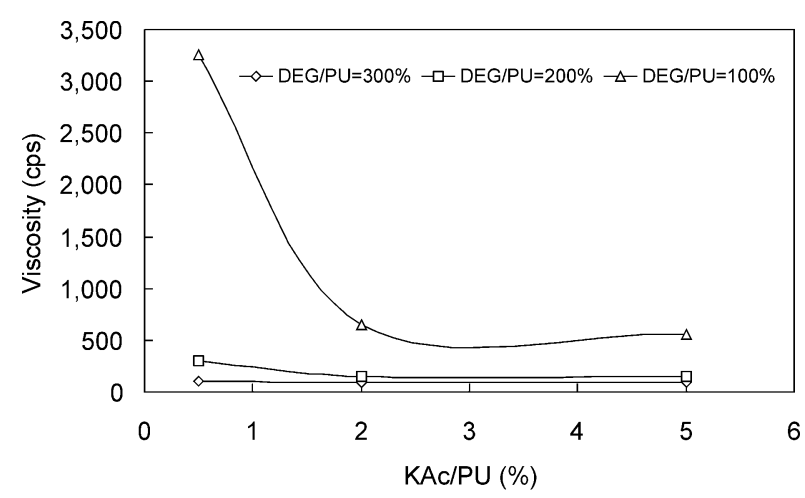

Fig. 9. Variation in viscosity (measured at $298 \pm 0.1 \mathrm{~K}$ ) of glycolysis products at $t=2 \mathrm{~h}$ with concentration of catalyst (KAc/PU).

\subsection{Purification of liquid product}

Glycolysis products consist mostly of polyol-containing materials (liquid products) together a small fraction of $\mathrm{CO}_{2}$, chlorofluorocarbons (CFCs), and hydrocarbons (gaseous products). The gaseous products at the top of reactor were first cooled with a condenser and then adsorbed by an active carbon filter before being vented to a fume hood. After the glycolysis $(t=2 \mathrm{~h})$, the mass 
Table 7

Viscosity of glycolysis products at $t=2 \mathrm{~h}$

\begin{tabular}{lllc}
\hline Viscosity $(\mathrm{cp})^{\mathrm{a}}$ & $\begin{array}{l}\mathrm{DEG} / \mathrm{PU}=300 \mathrm{DEG} / \mathrm{PU}=200 \mathrm{DEG} / \mathrm{PU}=100 \\
(\mathrm{mass} \%)\end{array}$ & $\begin{array}{c}\text { (mass\%) } \\
(\text { mass } \%)\end{array}$ \\
\hline $\mathrm{KAc} / \mathrm{PU}=0.5($ mass\%) 108 & 303 & 3252 \\
$\mathrm{KAc} / \mathrm{PU}=2.0($ mass\%) & 90 & 148 & 648 \\
$\mathrm{KAc} / \mathrm{PU}=5.0($ mass\%) & 91 & 150 & 551 \\
\hline
\end{tabular}

a Viscosity measured at $298.0 \pm 0.1 \mathrm{~K}$, in standard polystyrene (485 cps, at $298.0 \mathrm{~K}$ ).

Table 8

Recovery of polyol-containing liquid products at different distillation temperature ranges

\begin{tabular}{lllllll}
\hline $\begin{array}{l}\text { Sample } \\
\text { number }\end{array}$ & $\begin{array}{l}\text { Sample } \\
\text { mass } \\
(\mathrm{g})\end{array}$ & & $\begin{array}{l}\text { Unit stage } \\
\text { distillation }\end{array}$ & $\begin{array}{l}\text { 2nd Stage } \\
\text { distillation }^{\mathrm{b}}\end{array}$ & $\begin{array}{l}\text { 3rd Stage } \\
\text { distillation }^{\mathrm{c}}\end{array}$ & Residues $^{\mathrm{d}}$ \\
\hline A012-2 & 127.85 & $\mathrm{~g}$ & 1.51 & 87.93 & 13.22 & 25.19 \\
& & $\%$ & 1.18 & 68.78 & 10.34 & 19.70 \\
$\mathrm{~A} 015-2$ & 215.36 & $\mathrm{~g}$ & 2.19 & 100.47 & 19.43 & 93.27 \\
& & $\%$ & 1.02 & 46.65 & 9.02 & 43.31 \\
A018-2 & 164.25 & $\mathrm{~g}$ & 2.91 & 90.73 & 39.15 & 31.46 \\
& & $\%$ & 1.77 & 55.24 & 23.84 & 19.15
\end{tabular}

a $T_{\mathrm{g}}<518 \mathrm{~K}\left(T_{1}<529 \mathrm{~K}\right), T_{\mathrm{g}}=$ gas-phase temperature, $T_{1}=$ liquid-phase temperature.

b $T_{\mathrm{g}}=518-523 \mathrm{~K}\left(T_{1}=529-564 \mathrm{~K}\right)$.

c $T_{\mathrm{g}}=524-565 \mathrm{~K}\left(T_{1}=565-633 \mathrm{~K}\right)$.

d $T_{\mathrm{g}}>565 \mathrm{~K}\left(T_{1}>633 \mathrm{~K}\right)$.

e For formulations see Table 3; A***-2 means $t=2 \mathrm{~h}$.

percentages of liquid products remaining in the reactor are about 95.3 , 93.7 and $92.7 \%$ for $\mathrm{DEG} / \mathrm{PU}=300 \%$ and $\mathrm{KAc} / \mathrm{PU}=0.5,2$, and $5 \%, 87.7 \%$ for $\mathrm{DEG} / \mathrm{PU}=$ $200 \%$ and $\mathrm{KAc} / \mathrm{PU}=0.5 \%$ and $90.5 \%$ for $\mathrm{DEG} / \mathrm{PU}=$ $100 \%$ and $\mathrm{KAc} / \mathrm{PU}=0.5 \%$, respectively. As indicated in the results of the analysis of the glycolysis products, an adequate concentration of KAc and an adequate reaction time are $2 \%$ and $2 \mathrm{~h}$, respectively. The glycolysis products at $\mathrm{KAc} / \mathrm{PU}=2 \%$ and $\mathrm{t}=2 \mathrm{~h}$ were thus collected and distilled to investigate the properties of the distilled materials (polyol-containing liquid products). The recovery of polyol-containing liquid products for $\mathrm{DEG} / \mathrm{PU}=300200$, and $100 \%$ at $\mathrm{KAc} / \mathrm{PU}=2 \%$ and $t=2 \mathrm{~h}$ is summarized in Table 8 . The polyol-containing products are mostly in a temperature range of 518-523 $\mathrm{K}$ (gas phase temperature). The yields of polyol-containing products are $68.78,46.65$ and $55.24 \%$ for DEG/ $\mathrm{PU}=300,200$ and $100 \%$ at $\mathrm{KAc} / \mathrm{PU}=2 \%$ and $t=2 \mathrm{~h}$, respectively. The $M_{\mathrm{w}}$ of the polyol-containing liquid products at this stage is about 200 . Because the high molecular-weight residues remained in the still after $T>565 \mathrm{~K}$, the $M_{\mathrm{w}}$ of the polyol-containing liquid products is much lower than those of the original liquid products (listed in Table 6). The hydroxyl values of the polyol-containing liquid products at this stage are about 798.5-1013.3 $\mathrm{mg} \mathrm{KOH} \mathrm{g}^{-1}$, similar to that of DEG (i.e. $1057.3 \mathrm{mg} \mathrm{KOH} \mathrm{g}^{-1}$ ), thereby indicating that the dis- tilled materials may consist of excess DEG or the DEGcontaining polyols may be produced from the glycolysis of rigid PU foam.

The optimum temperature range for PU glycolysis is about $453-493 \mathrm{~K}$. Temperatures of about $473 \mathrm{~K}$ have thus proved to be sufficient for a rapid homogenization of the system and for complete glycolysis in 3-5 h [6]. In this study, the glycolysis temperature is about $496 \pm 3 \mathrm{~K}$. A higher temperature shortens the reaction time but results in a higher hydroxyl value (609-946 mg KOH $\mathrm{g}^{-1}$ ). However, the optimum hydroxyl value for polyol glycolysis products from rigid foams appears to be around $450 \mathrm{mg} \mathrm{KOH} \mathrm{g}^{-1}$ [6]. It would be helpful to compare the property profile of new foams from the recovered polyols of this study $(T=496 \pm 3 \mathrm{~K})$ to those commercially PU foams.

\section{Conclusion}

Glycolysis of rigid PU foam has been investigated to provide useful data for the recycling of scrap refrigerators. The experiments were performed under atmospheric pressure in a stirred flask kept at a constant temperature by a heating mantle. DEG and KAc were used as the solvent and the catalyst in the glycolysis system, respectively. The properties of glycolysis products such as hydroxyl value, mass mean molecular weight, viscosity and the conversion of the $-\mathrm{NCOO}$ - functional group in PU at different experimental conditions were analyzed. An adequate concentration of KAc and an adequate reaction time have been determined in this study. The recovery of polyol-containing liquid products can be achieved by the distillation of glycolysis products. However, further study would be helpful for recycling waste PU foams. Such research may include (1) determining the amount (ratio) of DEG consumed for different reaction conditions, (2) investigating the possibility for recycling the polyol-containing products as solvents instead of pure DEG, and (3) analyzing the properties of the new foams prepared from the recycled polyols.

\section{Acknowledgements}

The writers express their sincere thanks to the Union Chemical Laboratories, Industrial Technology Research Institute of Taiwan for financial support. The authors also wish to express appreciation to Dr. Cheryl Rutledge for her editorial assistance.

\section{References}

[1] Hopper JFG, Parrinello G, Parfondry A, Kroesen KW. Cell Polym 1992;11(5):388-96. 
[2] Hartel JJ. New developments in thermoset recycling and environmentally friendly processing systems. In: Proceedings of Polyurethanes World Congress, 10-13 October 1993. p. 218-23.

[3] Simioni F, Modesti M, Rienzi SA. Proceedings of 2nd International Conference of Cellular Polymers, 23-25 March, Edinburgh, UK, 1993.

[4] Weigand E, Rasshofer W, Herrmann M, Baumann GF, Nakamura M. Recycling of polyurethanes put into practice. In: Proceedings of Polyurethanes World Congress, 10-13 October 1993. p. 211-17.

[5] Hicks DA, Krommenhoek M, Soderberg DJ, Hopper JFG. Cell Polym 1994;13(4):259-76.

[6] Scheirs J, editor. Polymer recycling. UK: John Wiley \& Sons; 1998. p. 355-9.

[7] Kinoshita O. Process for decomposition of a polyurethane resin. US Patent 3632530 (1972).

[8] Frulla FF, Odinak A, Sayigh AAR. Conversion of scrap polyurethane foam to polyol. US Patent 3738946 (1973).

[9] Tucker B, Ulrich H. Novel process of reclaiming polyurethane foam. US Patent 3983087 (1976).

[10] Kondo O, Hashimoto T, Hasegawa H. Process for obtaining a polyol-containing homogeneous liquid composition useful for the production of rigid polyurethane foam from a rigid polyurethane foam. US Patent 4014809 (1977).

[11] Sheratte MB. Process for converting the decomposition products of polyurethane and novel compositions thereby obtained. US Patent 4110266 (1978).

[12] Ulrich H, Tucker B, Odinak A, Gamache AR. J Elast Plast 1979; 11:208-12.

[13] Simioni F, Bisello S. Cell Polym 1983;2:281-93.

[14] Simioni F, Modesti M, Rienzi SA. Cell Polym 1987;6(6):2741.

[15] Simioni F, Modesti M, Brambilla CA. Cell Polym 1989;8(5):387400.

[16] Modesti M, Simioni F, Rienzi SA. J Elast Plast 1992;24(4):288305.

[17] Simioni F, Modesti M. Cell Polym 1993;12(5):337-48.

[18] Kerscher J, Schwager H, RaBhofer W, Pfefferkorn R. Utech 1996;22:1-10.

[19] Borda J, Pasztor G, Zsuga M. Polym Degrad Stab 2000;68:41922.

[20] Simioni F, Modesti M, Rienzi SA. In: Proceedings of International Conference of Cellular Polymers, London, UK, 20-22 March 1991.

[21] Gassan M, Naber B, Neiss V, Moeckel P, Weissflog W. Preparation of recyclate polyols, and the use thereof in the preparation of polyurethanes. US Patent 5357006 (1994).

[22] Van der Wal HR. J Reinf Plast Compos 1994;13:87-96.

[23] Modesti M, Simioni F, Munari R, Baldoin N. React Funct Polym 1995;26:157-65. 